
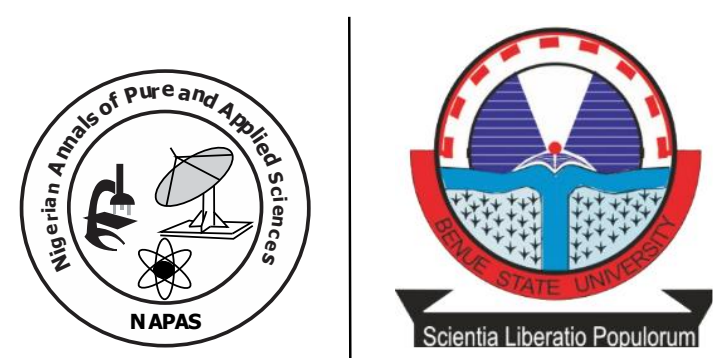

\title{
Application of Induced Polarization and Vertical Electrical Sounding to Locate Coal and Aquifers in Ojoma Akpa, Benue State
}

\author{
Ogah, V.E. ${ }^{1}$, Ikumbur, B.E. ${ }^{2}$ and Ogboji, M. E. ${ }^{3}$ \\ 1 \& 2Department of Geology, and ${ }^{3}$ Department of Building Technology \\ Benue State Polytechnic, Ugbokolo \\ Corresponding author: edabavin@gmail.com
}

\begin{abstract}
The study area Ojoma is located in Akpa district of Otukpo Local Government Area of Benue State, Nigeria. The area is underlain by Awgu Shale Formation that comprises shallow marine dark Shales, carbonaceous mudstones, limestones, siltstones and sandstones. The survey applied integrated geophysical techniques such as Induced Polarization and Vertical Electrical Sounding in order to locate a speculative coal deposit and prolific aquifers. ABEM Resistivity meter (Tetrameter SAS 1000) was used for the survey and Interpred 1D Software was used for processing, interpretation of field data and modeling of the subsurface. Four survey profiles (VES 1-4) were established with traverse lines between $1000-1300 \mathrm{~m}$ each. No coal deposit was discovered. However, two aquiferous zones were located at depths of $9-12 \mathrm{~m}$ and $25-50 \mathrm{~m}$ respectively. It is recommended that drilling of boreholes may be carried out to tap water from the second hydrogeologic zone between the depths of $25-50 \mathrm{~m}$. The survey result also explained the major features revealed by the survey in terms of the types of likely geological bodies and structures which gave rise to the resistivity curves and models, thereby extending geological knowledge of the area. The underlying structures which gave rise to the geological models are the existence of folded and faulted sedimentary beds in the area.
\end{abstract}

Keywords: Induced Polarization, Vertical Electrical Sounding, Resistivity, Aquifers, Awgu Shale Formation 


\section{Introduction}

The study area is called Ojoma community in Akpa district of Otukpo Local Government Area of Benue State, Nigeria. The area investigated lies within the Cretaceous sediment in the lower Benue Trough, Nigeria.

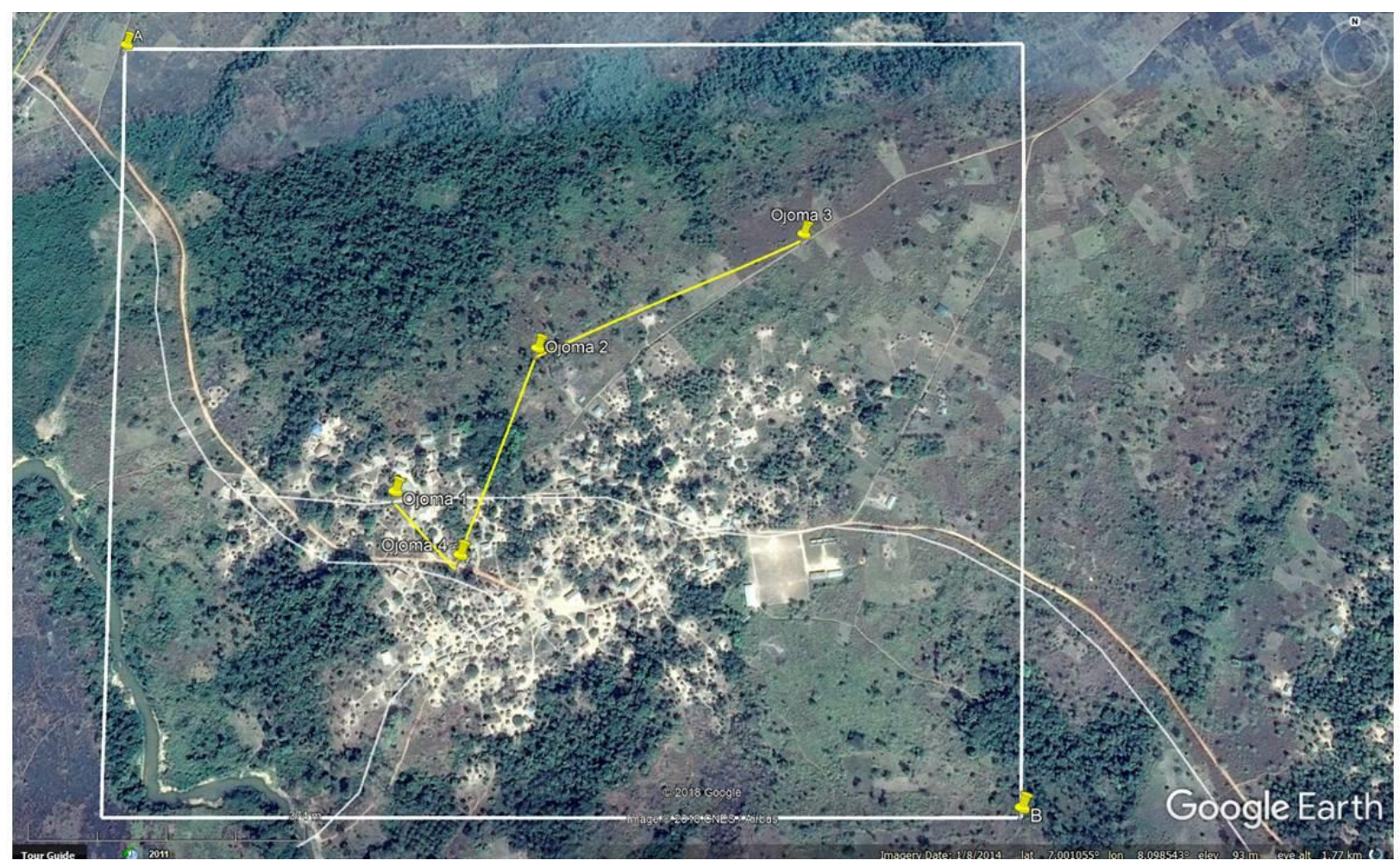

Figure 1: Location map of Ojoma as imaged by Google Earth

Induced Polarization (IP) and Vertical Electrical Sounding (VES) geophysical techniques were jointly employed in the survey. The survey was aimed at locating coal beds and depths of water bearing formations (aquifers) in the area. Integration of potential fields data from Electrical Potential methods such as IP and VES is used to resolve several questions in many geologic provinces. Another point to integrated potential field method; is that it sets limits to the depth, size, areal extent e.t.c of each body causing an anomaly. Complex structures can be interpreted and modeled with confidence using the integration of IP and VES. The quality of the solution is governed by the variety of constraints. For example if IP can input a minimum and maximum depth to an anomalous zone and detect the presence of conductors, sulphide and carbonaceous or graphite formations, VES measures resistivity variation vertically using schlumberger array and can assist in determining the lithology and the configuration of the anomalous zone.

Coal is an organic sedimentary rock that forms from the accumulation and preservation of plant materials buried millions of years ago, usually in a swampy environment. Coal comprises carbon of vegetative origin, the vegetation or plants contain $\left(\mathrm{C}_{6} \mathrm{H}_{12} \mathrm{O}_{6}\right)$ and other impurities. The dead buried plants then loose $\mathrm{H}_{12}$ and $\mathrm{O}_{6}$ due to evaporation. The accumulation of the carbon $\left(\mathrm{C}_{6}\right)$ gradually leads to the formation of coal. In Benue state coal is found in Owukpa and some traces at Okpiko, Edumoga areas

Mohammed et al, (2016) reveals that coal have high resistivity from few hundreds of ohmsmeter to few thousands ohms-meter Geoelectrical measurements have been used to detect aquifers and coal deposits in many countries of the world including Nigeria.

Geophysical surveys are necessary steps to achieve better targeting of the resources being sought as well as reasonable knowledge of possible factors that may indicate these resources. Induced Polarization is one geophysical technique used to detect massive deposits as well as delineate areas of mineral concentration. The controlling factor for choice of these geophysical techniques are the effectiveness and simplicity of 
equipment and ease of interpretation of data (Mohammed et.al, 2016).

\section{Local Geology Awgu Shale Formation}

The area of investigation lies within Awgu shale Formation. The Awgu group comprises very soft, shallow marine dark shales and carbonaceous mudstones with occasional muddy limestones and siltstones as well as a narrow band of sandstone known as the Agbani sandstone formation which is generally fine to medium grained and moderately cemented (Ogah, 2017). The area under study has an anticlinal structure with the formation striking NE-SW and dipping to the west.

The area has mineral resources such as brick clay, kaolinite clays, construction materials (Laterite, sandstones and plaster sands). Pyrite, thin shaley limestones e.t.c. the Awgu Formation is succeeded by the Nkporo shales in the northwestern part of Ojoma.

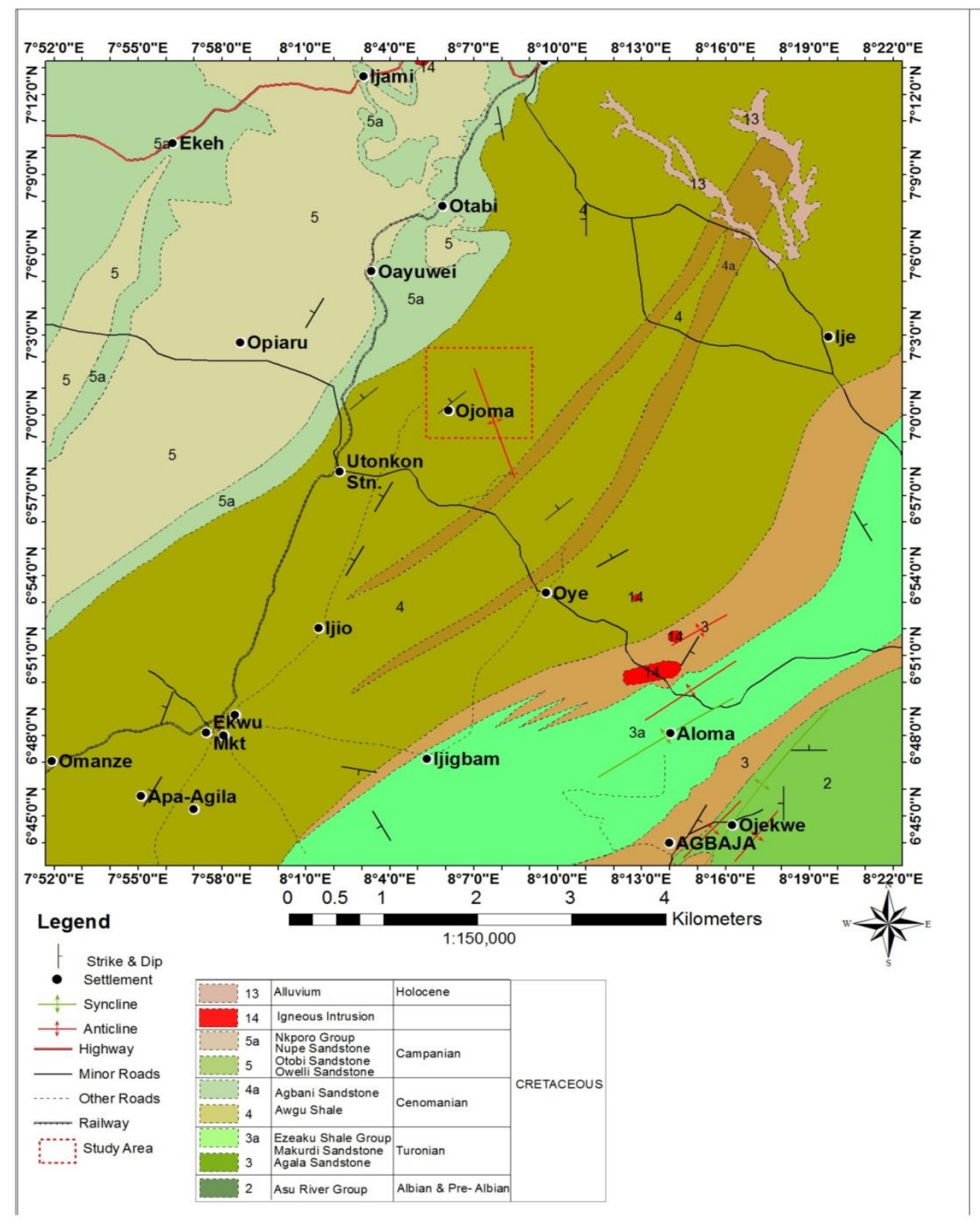

(v) Camera, (vi) Geologic hammers, (vii) Cutlasses, (viii) Tape,

(ix) Diggers, (x) Shovels, (xi) Hoes (xii) Field notebook.

Geophysical electrical potential methods were employed, and here the induced Polarization and the Vertical Electrical sounding techniques were integrated. Resistivity measurements were conducted using resistivity meter (ABEM Terrameter SAS 1000) connected to an external heavy duty Battery. The Schlumberger electrode configuration was used. Four survey profile lines were chosen. Large electrode spread between 
1000-1300 m corresponding to traverse lines with average depth probe of $100 \mathrm{~m}$ was used in each of the survey profiles. The four electrodes hammered into the ground at predetermined distance consist of two current and two potential electrodes. Current is passed through current electrodes into subsurface. The potential electrodes measure potential difference from the electrical current injected. The real resistivity is calculated by using inversion method and read from the resistivity meter. One way to measure IP is to compare ground resistivity as determined by direct current with the apparent impedance, determined by alternating current having a frequency of between 0.1 to 0.5 cycles per second. Any difference in the two measurements suggests the presence of conductors. For interpretation of the field data, Interpred ID software was used. Pitting was carried out at a point of interest and well $\log$ was studied. Conceptual models of the subsurface were created. The theoretical anomaly of the models calculated (forward modeling) and compared with the observed anomaly. The model parameters were then adjusted in order to obtain a better agreement between observed and calculated anomalies.

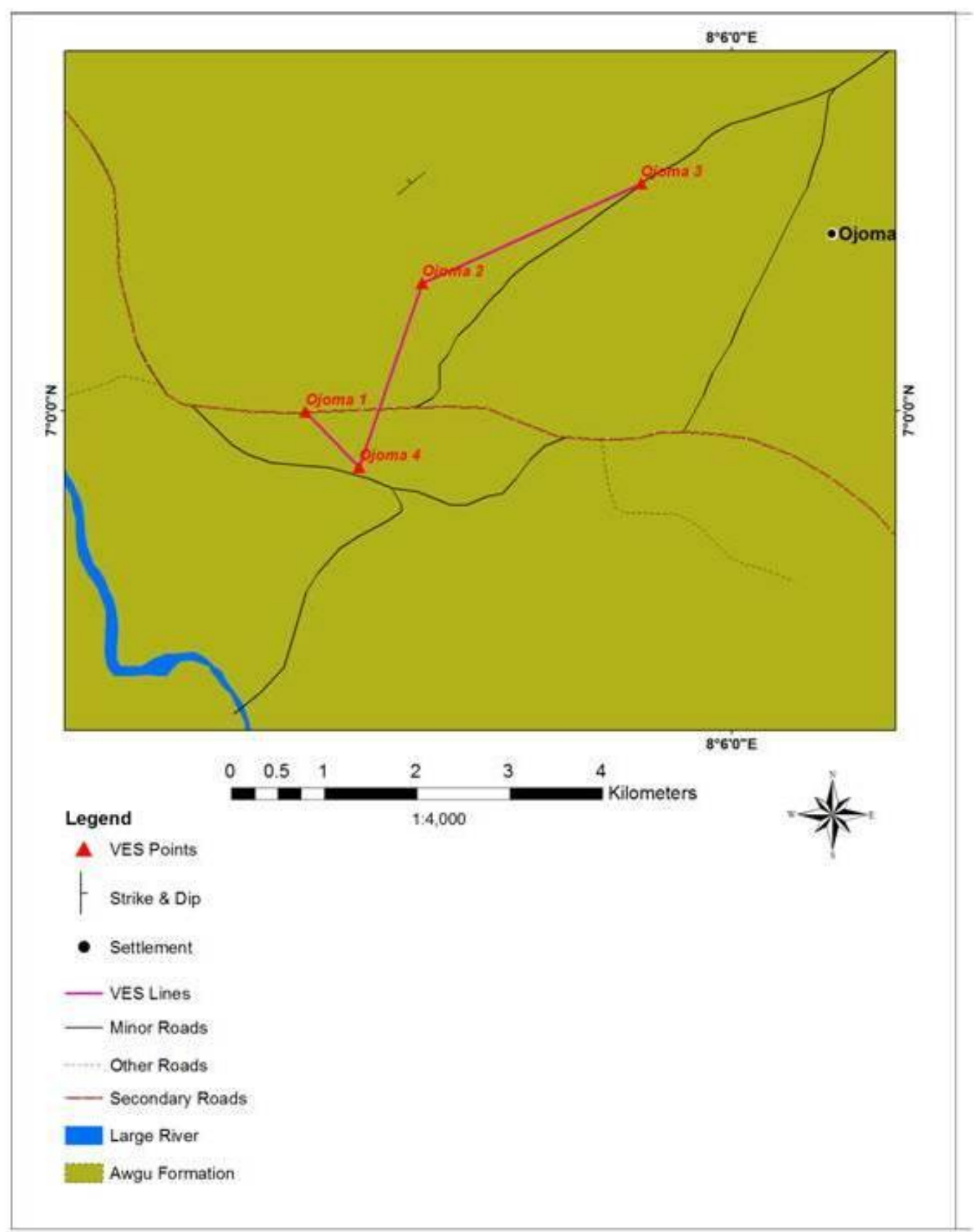

Figure 3: Map showing survey profiles (VES lines 1-4) superimposed on the geology of the study area 


\section{Results and Discussion}

The readings from the field are given in Figures 5-8 and illustrated as electrical resistivity curves and models. Interpretation of the obtained field data and assessment of the VES curves were guided by knowledge of the geology of the area. Removing the vegetative cover from the surface of the earth in the study area lies soft clayey, shaley mudstone. Between 1-5m below the surface is a geologic layer characterized by dark shaley carbonaceous mudstones with thin shaley -limestones. It is the dark shaley carbonaceous deposit that some residents of Ojoma referred erroneously as coal. Hence there is lack of evidence from the geophysical survey and investigation carried out by pitting that the area has coal deposit. The moderately high resistivity values of $341.14 \Omega \mathrm{m}$ in profile 2 or VES 2 (Figure 6 ) and $650.68 \Omega \mathrm{m}$ in profile 3 (Figure 7) is either as a result of an organic rich formation (carbonaceous mudstone section) or the area of over-thrusting of an older denser bed over younger beds. A layer or section with consistently high resistivity values of above $500 \Omega \mathrm{m}$ to few (25 ) thousands ohms meter is most probably the area to host coal, because coal is attributed to high resistivity. The high concentration of organic materials found in coal; constrains the pore space and reduces the pore connectivity making this sedimentary rock highly restive when compared to other sedimentary rocks (Andi Ilham, 2008). Consequently the measurements here do not provide the characteristic high resistivity normally associated with coal. However sufficient groundwater for rural water supply is found within thin sandstone layers (MacDonald, 2001). Aquicludes such as fine to medium clay rich sandstone and coarse grained siltstone lithologies recharged by near sources perennials streams and rivers harbor good quantity of water. This is evident in Figure 4, with shallow aquifer revealed in VES 2,3, and 4 occurring between 9$12 \mathrm{~m}$ depth. This hydrogeological unit is traceable to a hand dug well in Ogah Edaba's compound were water is mined from the unit at a depth of $10 \mathrm{~m}$ measured in May 2018. However as the rain stops, the shallow tropical soil quickly dries out and water-level in the well rapidly decline. The large river south-west of Ojoma recharge wells in the area (Figure 3).

A larger, deeper and prolific aquifer is encountered at depth of $46 \mathrm{~m}$ for VES $1,25 \mathrm{~m}$ for VES 2, 22m for VES 3 and $35 \mathrm{~m}$ for VES 4 with average saturated water bearing horizon thickness of $10.3 \mathrm{~m}$ (Figure 4 ).

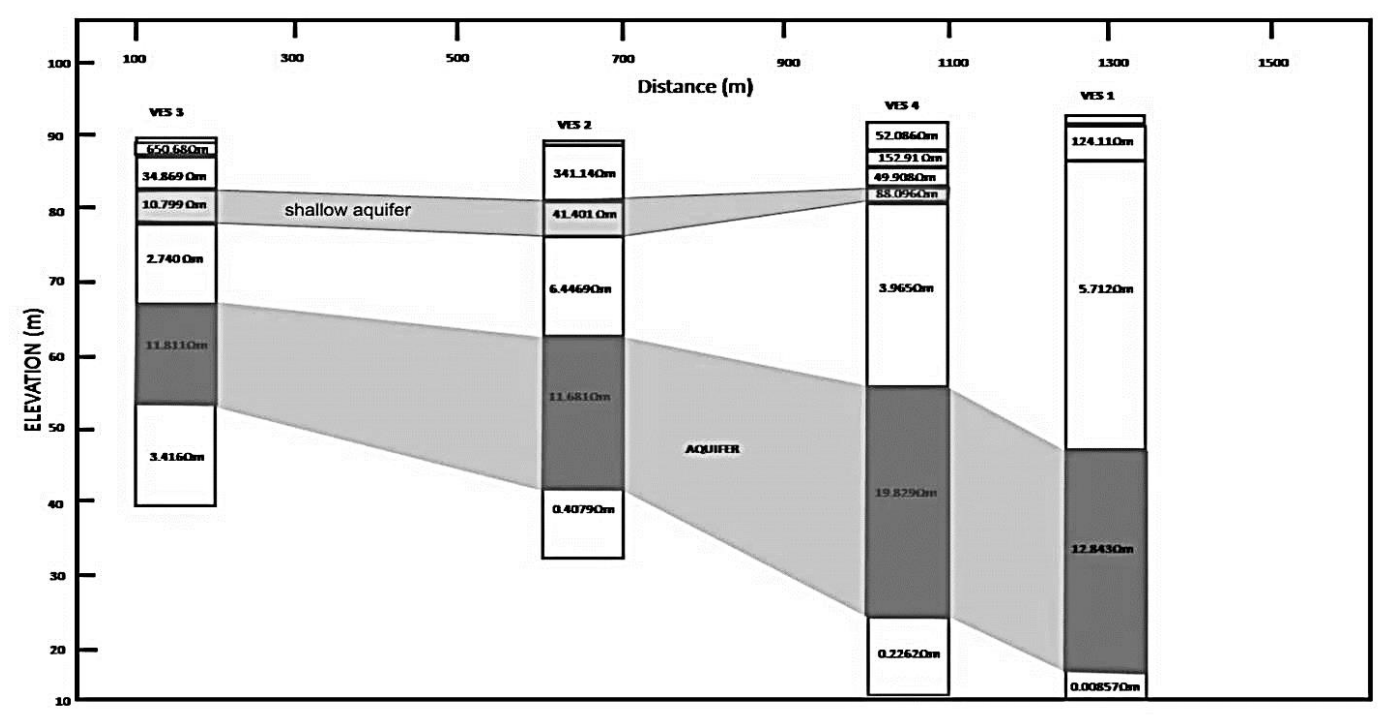

Modeling of sources in theory replicate the anomalies recorded in the survey. That is, given a model that is a suitable physical approximation to the geology of the area studied. The interpretation given here can be correlated to rock composition or structure or both.
In Figure 5 (VES 1), a normal fault with one high-density layer is observed. The model characteristics depict lithology variation with depth. 

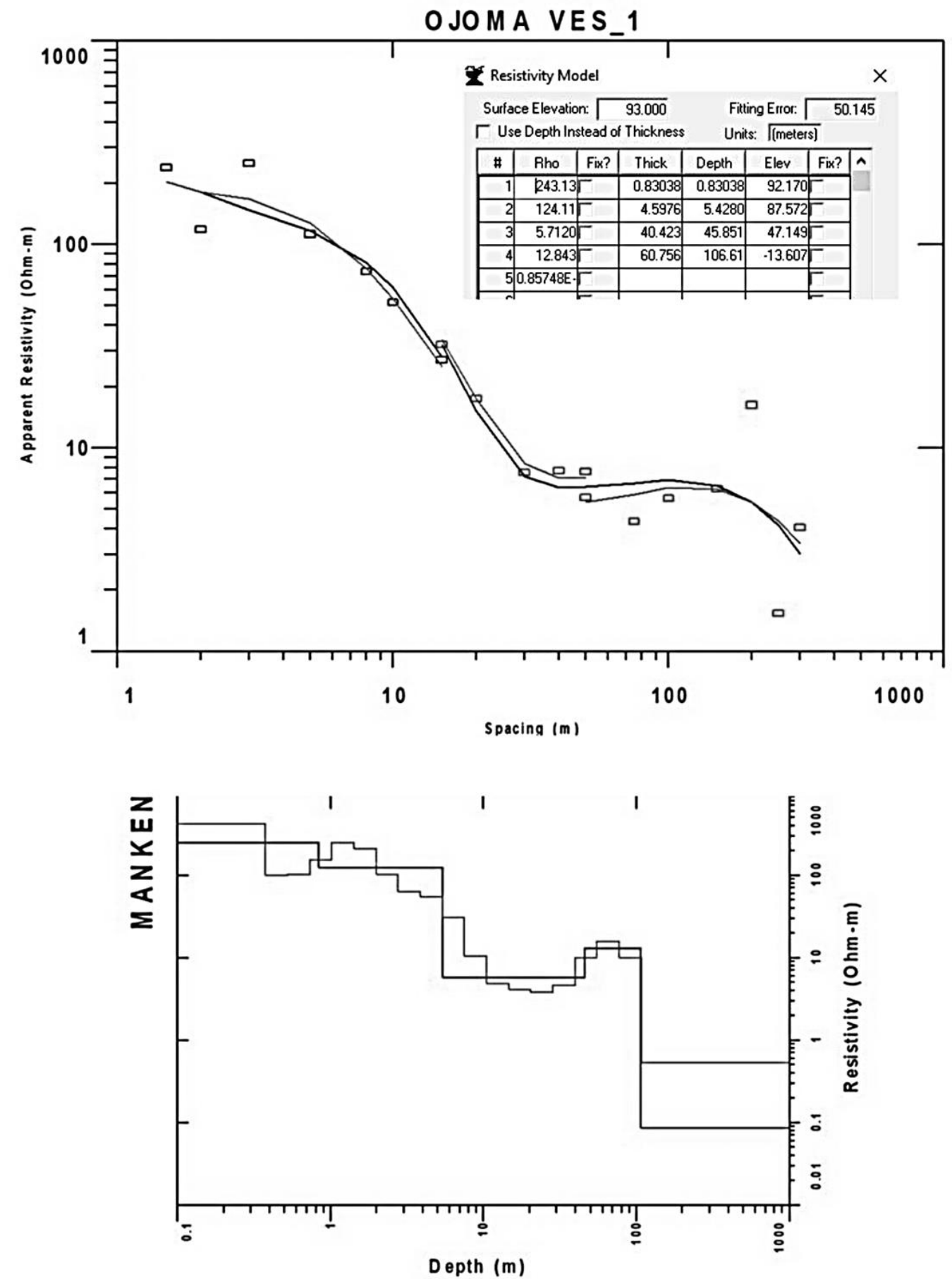

Figure 5: Electrical Resistivity Signature and Geological Model for VES 1

In VES 2 (Figure 6), the signal characteristics reflected in the curve and geologic model is typical of a normal faulted anticline. The structure reflects a sedimentary sequence of density values that increase with depth and a faulted basement uplift on the right side of the model. This structure produces a broad maximum anomaly signature indicating the areal extent of the anticline section. The magnitude of the minimum anomaly is governed by density contrasts and the thickness of the sedimentary sequence. 

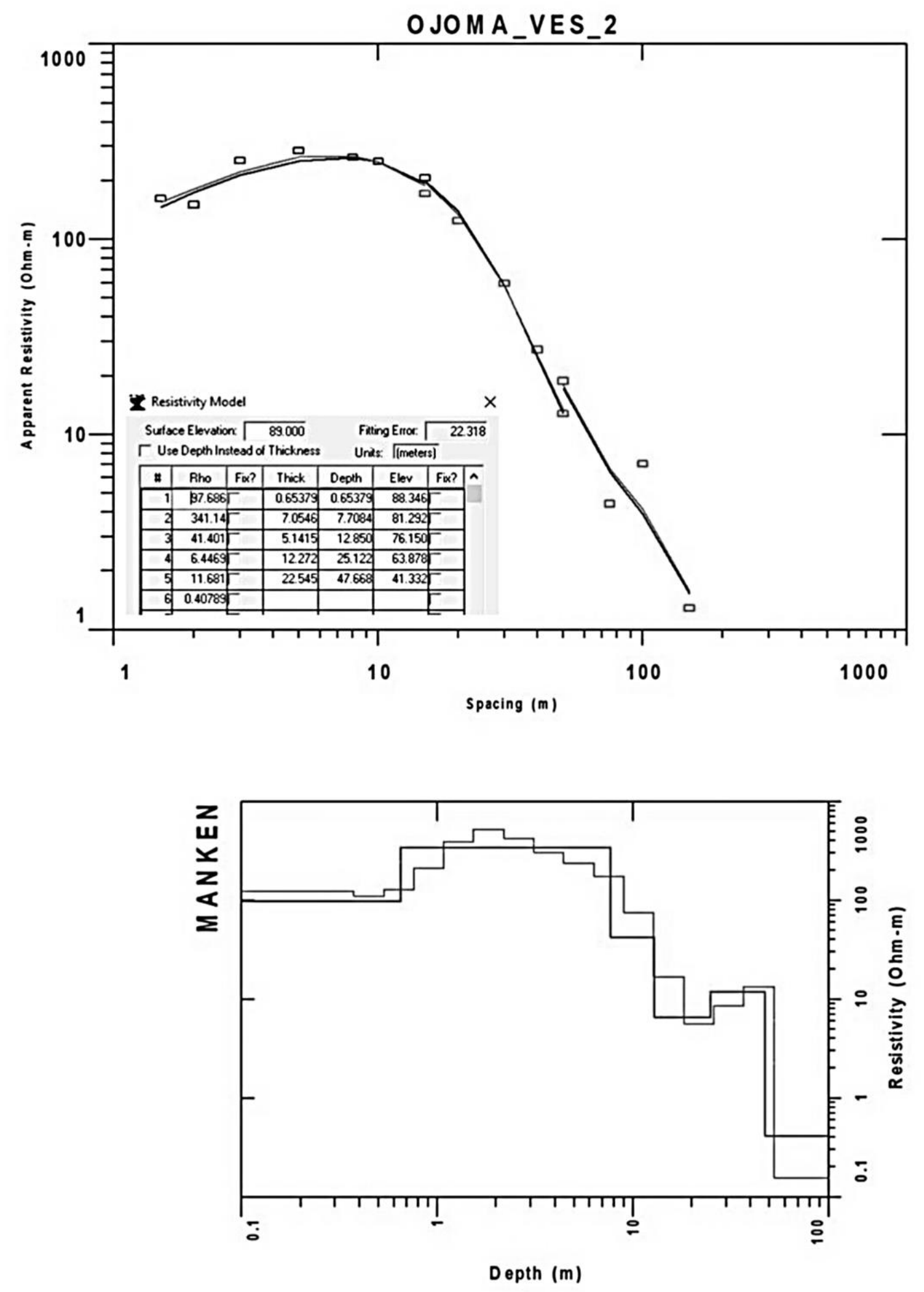

Figure 6: Electrical Resistivity Signature and Geological Model for VES 2

In VES 3 (Figure 7), the anomaly characteristics in the geological model is valid for dipping sedimentary fault beds, in which an overthrusted bed is substantially offset which could represent the thrusting of older bed over younger beds. The denser bed intruding into a sedimentary sequence may be inferred even from the inflection on the resistivity curve. 


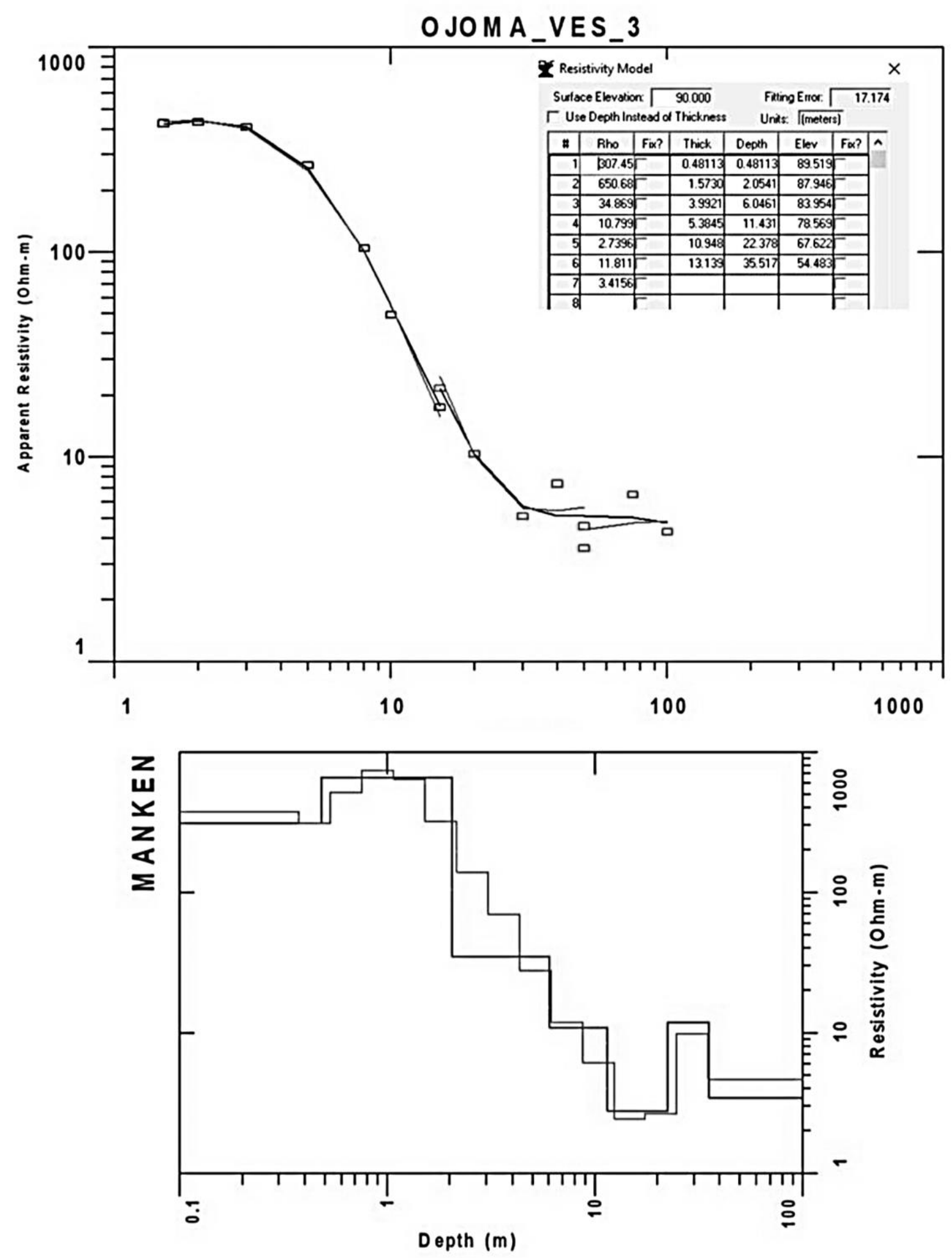

The model in Figure 8 (VES 4) is an depth. The areal or lateral extent of the basins or grabens are delineated by or expressed as a example of a more complicated geology. The rock model structure reveals both a folded and faulted minimum closure surrounded by higher frequency sedimentary syncline with increasing density with maximum closure due to sedimentary warping. 

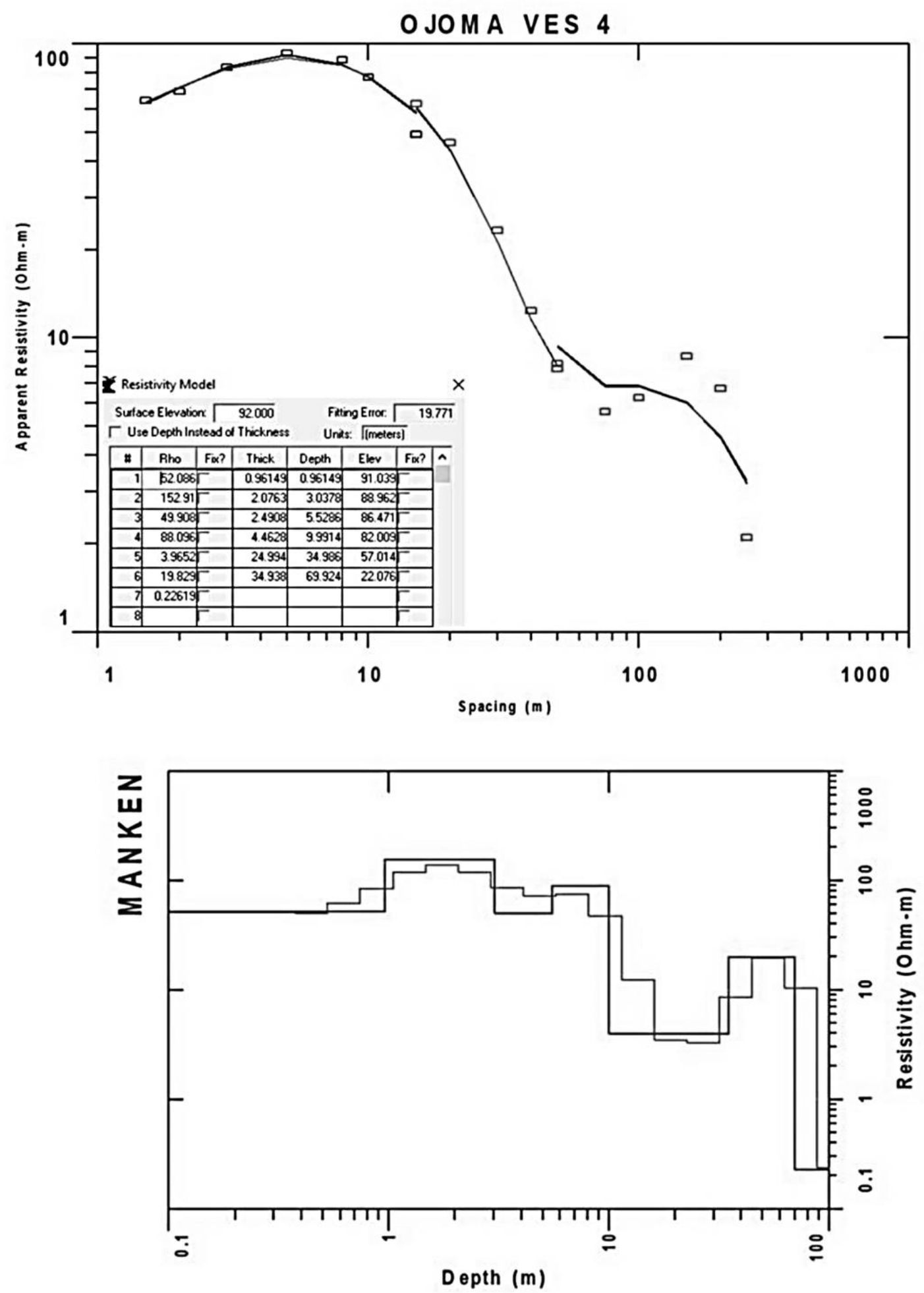

Figure 7: Electrical Resistivity Signature and Geological Model for VES 4

\section{Conclusion}

There is no evidence from the geophysical survey and the investigation carried out by pitting that the area studied has coal deposit. No information is available from coal outcrop evidence within the survey area or nearby (although the area is a favourable geologic province for coal).

Two hydrogeologic zones were identified. The first water bearing unit occurs between 9$12 \mathrm{~m}$. The lithologies have little porosity and permeability. Shallow traditional wells mine this water source and supply high yields when the shallow zone is saturated. As a result, shallow boreholes are not recommended in the area. Prolific aquifer water supply is expected at a greater depth of $22 \mathrm{~m}$ and below. It is recommended that drilling of boreholes may be carried out to tap water from the second hydrogeologic zone between the depths of 25$50 \mathrm{~m}$. 
The geologic models shown have been limited to basic structures for the express intention of illustrating the variation of signature characteristics due to variations in rock properties. The earth - models are consistent with what has been observed, that is suitable physical estimate to the known geology.

\section{References}

Andi Ilham S. (2008). Coal layer identification using Electrical Resistivity Imaging Method in Sinjai Area South Sulawesi Journal of Physics. Conference Series 979 012048.1

MacDonald, A.M. (2001). Report on visit to a water Aid project Nigeria. British Geological Survey Internal Report. IR/101/18.

Mohammed, M.A., Adewumi, T., Ahmed, A.L., \& Lawal, K.M. (2016). Electrical Resistivity Imaging of a coal Deposit at Tai Area of Gombe State, North Eastern Nigeria. Journal of Environmental and Earth Science, 6 (6), 55.

Nazarenko, M.Y, Kondrasheva, N.K and Salty kova, S.N. (2018). Electrical Resistivity of coal and oil shales. Coke and Chemistry. Koksi khimiya. 61 (5), 35-39.

Nwachukwu, S.O. (1972). The Tectonic Evolution of the south portion of the Benue Trough. Geological Magazine109, 411-419.

Ogah, V.E., Ikumbur, B and Ogboji, M.E. (2017). Delineation of groundwater prospective zones using remote sensing and airborne Magnetic data. Journal of Natural and Applied sciences, Vol. 5, No.2. A publication of Faculty of Natural and Applied Sciences, Nasarawa State University, Keffi. pg 24.

Ogah, V.E., Ikumbur, B.E. and Emmanuel, J.O. (2015) Geophysical survey for groundwater development at Benue State Polytechnic, Ugbokolo, Benue State, Nigeria. Nigerian Journal of Pure and Applied sciences. Publication of the Faculty of Sciences, Benue State University, Makurdi 119-126.

Roy, A. and Apparao, A. (1971). Depth investigation in direct current methods. Geophysics, 36, 943-959.

Ruffet, C. Darot, M. and Guenguen, Y. (1995). Surface Conductivity in rocks, A review. Surveys in Geophysics, 16, 183-105. 